\title{
EXTENDING THE DECISION-MAKING CAPABILITIES IN REMANUFACTURING SERVICE CONTRACT BY USING SYMBIOTIC SIMULATION
}

\author{
Evandro Leonardo Silva Teixeira ${ }^{1}$, Benny Tjahjono ${ }^{2 *}$, Sadek Crisóstomo Absi Alfaro ${ }^{3}$, Richard \\ Wilding ${ }^{4}$. \\ ${ }^{1}$ Engenharia Automotiva, Faculdade do Gama, Universidade de Brasília, Brazil \\ ${ }^{2}$ Centre for Business in Society, Coventry University, UK \\ ${ }^{3}$ Departamento de Engenharia Mecânica, Universidade de Brasília, Brazil \\ ${ }^{4}$ Supply Chain Research Centre, School of Management, Cranfield University, UK
}

\begin{abstract}
Remanufacturing is a critical enabler of a resource efficient manufacturing industry that has long been associated with high value products. Over time, the commercial relationship between customers and service providers has been made through the fulfilment of rights and obligations under remanufacturing service contracts. Nonetheless, financial analysis to evaluate the contract terms and conditions are becoming increasingly difficult to conduct due to complex decision problems inherent in remanufacturing systems. In order to achieve better and safer decisionmaking to shape the business strategies, remanufacturers often employ computer-based simulation tools to assess contractual obligations and customers' needs. This paper discusses the roles of a symbiotic simulation system (SSS) in supporting decision-making in remanufacturing systems. An industrial case study of power transformer remanufacturing illustrates how SSS can support contract remanufacturers in managing service contracts planning and execution. By linking the simulation model to the physical system, it has been demonstrated that the capabilities of the remanufacturers to make critical decisions throughout the entire service contract period can be extended.
\end{abstract}

Keywords: Service Contract, Symbiotic Simulation, Remanufacturing, Decision-making *Corresponding author

Address: Centre for Business in Society, Coventry University, Priory Street, Coventry CV1 5FB, United Kingdom. 
Email: benny.tjahjono@coventry.ac.uk 


\section{INTRODUCTION}

Remanufacturing is the rebuilding of a product to specifications of the original manufactured product combining reuse, repair and replace of worn parts (Grubbström and Tang 2006; Aksoy and Gupta 2010; Ilgin and Gupta 2012). Many Original Equipment Manufacturers (OEMs) of automobiles and spare parts, electric motors, tyres, telephones, television, vending machines, photocopiers, toner cartridges, etc. (Statham 2006), in the last ten years, have decided to remanufacture their products due to both commercial reasons and environmental pressures. Remanufacturing usually begins with harvesting good quality spare parts of components from supposedly unrepairable or end-of-life products. The components will subsequently be cleaned, and checked or tested, before being reassembled, together with some new components, if necessary, to make up new products (Savaskan, Bhattacharya and Van Wassenhove 2004). To ensure the desired technical and performance specifications, the remanufactured products will undergo a thorough quality check. In some circumstances, the products are upgraded by adding, improving, or strengthening parts that are prone to failure.

In recent years, remanufacturing has gained economic importance in industrialised nations. For instance, the USA which is the largest producer, consumer and exporter of remanufactured products, reached more than $\$ 43$ billion in total production of remanufactured goods, supporting over 180,000 full-time jobs (U.S. International Trade Commision 2012). Caterpillar Inc., in particular, is reported to have remanufactured over $\$ 3.5$ billion worth of parts and components for diesel and turbine engines, construction and mining equipment, electric power generators, railroad locomotives, and railcars in North America (Lund and Hauser 2010). Remanufacturing is also set to become increasingly important for the EU market, generating around $€ 30$ billion (\$34 billion) and employing around 190,000 people in EU countries (Parker et al. 2015). For the British economy alone, remanufacturing activities have contributed around $£ 2.4$ billion, creating thousands of skilled jobs (Smith-Gillespie et al. 2014). The value-added through remanufacturing has encouraged global manufacturing companies to include remanufacturing of used products in their offering portfolio.

Remanufacturing has been widely adopted in the electricity and energy generation sector, for instance in the recovery of a large number of high voltage power transformers, which are also considered high value assets. Customers, i.e. the electricity providers and distributors, often outsource the remanufacturing of power transformers to the Original Equipment Manufacturers 
(OEMs) or third-party repairers or retrofitters. Outsourcing the repair, reconditioning and remanufacture of large numbers of assets such as transformers is particularly desirable when the customers do not necessarily possess skills, knowledge and resources to carry out the tasks (AliMarttila et al. 2017). It also frees up the customers from risky capital investment in building the remanufacturing facilities and thus reduces overhead costs. As transformers are considered high value electrical assets, the repairers and remanufacturers usually accept all transformers being returned, irrespective of the quality of the products (Clottey, Benton and Srivastava 2012). In this type of product recovery practice, the transformer remanufacturers bear the risks in ensuring the transformers are returned to the customers on time and, more importantly, as new.

While the basic concept of remanufacturing is simple, the management of remanufacturing system activities has become more difficult, requiring particular attention by the remanufacturers. Complex management of supply and demand of used components can make inventory management in remanufacturing businesses complicated (Lundmark, Sundin and Björkman 2009). Precise knowledge about the real-time condition of the products in use, and thus what components should be replaced, repaired or reused, is often limited. As a consequence, the reprocessing routines to be done can only be identified after the used products have been completely disassembled. As a consequence, the labour costs, and spare parts which make up the total remanufacturing costs, are often difficult to calculate, especially when the total remanufacturing process time is difficult to predict. This makes accurate production planning and control of the remanufacturing systems an arduous task.

Apart from the challenges and uncertainty surrounding the remanufacturing systems, the assessment of remanufacturing service contracts (SCs) is, in fact, complex. The remanufacturers should always evaluate the contract terms and conditions and weigh these against the potential revenues. The evaluation of SCs becomes even more difficult whenever contract agreement payment terms are based on the so-called 'core quality conditions', where remanufacturing cost (RC) is not fixed but rather changes in accordance with the condition of the cores (used products) received (Robotis, Boyaci and Verter 2012). Under this type of payment terms, the customers are usually willing to pay for repair only services and, as a consequence, the remanufacturers do not necessarily have information about the outcomes until the service contract expires. In a contractual budget based on the core quality conditions, often required for high asset value, predicting spare parts provision or profitability of the SCs is not straightforward, especially when the remanufacturers handle a large number of SCs from 
different customers with different terms, clauses and conditions. Therefore, in order to carry out a more reliable evaluation of SCs, remanufacturers need to evaluate the performance of existing contracts and the remanufacturing system's capabilities against the customer's needs.

Traditionally, simulation modelling has been employed to assess potential impacts from the contractual terms and commercial conditions, by taking into account relevant aspects of the business process. Using simulation, service providers can carry out experiments, based on existing knowledge and previous experience, for the required operations before committing to any changes, including capital investment, on the shop floor. However, this type of simulation model typically runs from an initial state and does not directly represent the actual state of the system, as it uses previously known knowledge, historical data, and assumptions. In the case of remanufacturing SCs with core quality conditions-based payment, RC, materials and routines can only be determined during the contract execution (in-service phase) and not before the contract is executed; the service providers would, in this case, need real data and to treat the simulation model as a 'twin' to the real system, with the expectation that the predictability of future events can be improved and thus ultimately provide more effective decision-making.

To do so, some important features and elements from the remanufacturing process (i.e., costs, materials, resources, and routines) must be mapped, and their current status is triggered whenever a simulation experiment is initiated. By using real-time acquisition technology, virtual remanufacturing system components will not start from an initial state but bring to the simulation model actual service contract outputs as well as remanufacturing system conditions and state. In linking the simulation model and the remanufacturing system, inconsistencies and uncertainties related to contract execution can, in turn, be forwarded to the simulation model. In theory, this would benefit the remanufacturers with informed decisions and viable alternatives coming from experiment results and could potentially improve their capabilities in making critical decisions throughout the entire service contract period.

The research described in this paper aims to extend the decision-making capabilities of the remanufacturing service contract providers using simulation modelling. The ultimate goal is to better understand how the remanufacture service contract analysis could benefit from a close association between the simulation model and the physical remanufacturing systems. The paper is organised as follows. Section 2 presents the literature review showing the most recent work in the research area. Section 3 discusses the research methodology employed. Section 4 highlights 
the system development with a detailed business description, relevant performance measures, and symbiotic simulation model. Section 5 presents an industrial case and some simulation experiments for service contract performance analysis. The last section presents the concluding remarks and suggestions for future work.

\section{LITERATURE REVIEW}

In order to better understand the previous work and contributions in this area of research, a review of the literature was carried out. Academic databases, such as Scopus, IEEE Explore, ScienceDirect, Elsevier, Emerald Insight, Wiley Online Library and Google Scholar, hosting journals papers, conferences proceeding, and textbooks were searched to retrieve the relevant papers. A combination of keywords (i.e., "manufactur*", "remanufactur*”, "transformer", "modelling or modeling", "contract", "simulation", "symbiotic simulation", "cyber physical system", "internet of things") and their synonyms were also employed. The time frame covers 10 years of publication from 2009 to 2018. Table 1 summarises the most relevant literature being reviewed. 
Table 1: Most relevant literature related to the research theme

\begin{tabular}{|c|c|}
\hline Reference & Description \\
\hline Calvi et al. (2015) & A simulation-based optimisation (SBO) study for better resource allocation within the testing and refurbishing processes \\
\hline Fanchao et al. (2009) & $\begin{array}{l}\text { Developed a symbiotic simulation control system for proactive analysis for better inventory control and management of lubricant additive } \\
\text { industry }\end{array}$ \\
\hline Graham et al. (2015) & $\begin{array}{l}\text { An overview of remanufacturing and the general use of Performance Measurement and Key Performance Indicators (KPIs) and also new } \\
\text { formulated KPI designed specifically for remanufacturing }\end{array}$ \\
\hline Kang et al. (2016) & Virtual Reality-based simulation system to assess transformer overhaul and development process \\
\hline Kück et al. (2016) & A data-driven simulation-based optimisation method to schedule complex stochastic and dynamic manufacturing system \\
\hline Lehr et al. (2013) & System dynamics model for OEM in the electronics industry to test different value recovery strategies in a closed-loop supply chain setting \\
\hline Mashhadi et al. (2015) & $\begin{array}{l}\text { Developed a stochastic optimisation model to help remanufacturing companies decide about the most profitable upgrade level for incoming } \\
\text { used products }\end{array}$ \\
\hline Noack et al. (2011) & Designed an online simulation model for application in the Semiconductor Manufacturing Industry \\
\hline Sharpe et al. (2018) & Cyber Physical System (CPS) concept application in re-use, refurbishment and recycling of Electrical and Electronic Equipment (EEE) \\
\hline Slotina \& Dace (2016) & A decision support tool for implementation of remanufacturing in an enterprise \\
\hline Teixeira et al. (2012) & $\begin{array}{l}\text { Proposed a novel framework to link Prognostics and Health Management (PHM) and Product Service Systems (PSS) to support decision- } \\
\text { making through online simulation. }\end{array}$ \\
\hline Tjahjono \& Jiang (2015) & $\begin{array}{l}\text { Developed a framework of symbiotic simulation that can be used to improve the performance of a production system controlled by an } \\
\text { enterprise resource planning (ERP) system }\end{array}$ \\
\hline Umeda (2013) & A methodology of simulation modelling and analysis of supply chain systems with reverse logistics flows with product recovery practices \\
\hline Wang \& Wang (2018) & $\begin{array}{l}\text { Proposed a system architecture for a digital twin-enabled Cyber-Physical System to support remanufacturing operations in Waste Electrical } \\
\text { and Electronic Equipment (WEEE) }\end{array}$ \\
\hline Yanikara \& Kuhl (2015) & Modelling and analysis framework for reverse logistics network with decision support tool \\
\hline Zhang et al. (2018) & Proposed a real-time scheduling and a Pareto-based optimiser for better dynamic management of remanufacture resources \\
\hline
\end{tabular}


Critical analysis of the literature reveals that discrete event simulation (DES) and system dynamics have been highlighted as the most useful simulation techniques employed in remanufacturing analysis. For instance, Umeda (2013) designed a discrete simulation model to assess supply chain systems with product recovery practices. With the proposed simulation model, supply chain management concerns arising from the reverse logistics operations (such as supply and vendor selection, used product collection, spare parts for remanufacturing) can, in turn, be virtually investigated. The test bed simulation system emulates reverse logistics activities in supply chain scenarios, including used product collection, spare parts remanufacturing, and usable material recycling. Likewise, Yanikara \& Kuhl (2015) presented a framework to compare alternative reverse logistics network configuration based on productivity and sustainability performance metrics. The decision support tool provides an effective method for evaluating alternative product recovery scenarios.

Similarly, Calvi et al. (2015) present a simulation-based optimisation study for better allocation within the testing and refurbishing process. Experimental results have shown how a distinct configuration can influence device cost and product recovery throughput. Yet, the simulation model may be used to analyse capital investment and design refurnishing systems for new products. Mashhadi et al. (2015) developed a stochastic optimisation model to deal with uncertainties in take-back and inventory planning systems. The model helps in determining the best upgrade level for a received product with a certain quality level, aiming to maximise profits. Based on the simulation results, remanufacturing companies can decide on the most profitable upgrade level for incoming used product. Slotina \& Dace (2016) designed a decision support tool based on system dynamics modelling to implement remanufacture practices in an enterprise. Experiment results suggested that for some used products, remanufacturing can offer a feasible opportunity to produce a new product by using used parts, with energy consumption reduction and a saving on raw materials.

Some researchers have decided to expand decision support capabilities from modelling and simulation tools. For instance, Teixeira et al. (2012) designed a framework to link Prognostic and Health Management with Product Service Systems (PSSs) through online simulation. With the proposed framework, a simulation tool could be used to support short-term operational decisions and better management of manufacturing systems. Moreover, Tjahjono and Jiang (2015) proposed a framework of symbiotic simulation that can be used to improve the performance of a production system controlled by an enterprise system. With the proposed 
symbiotic model, simulation results could be periodically updated in near real-time, solving tardiness in customer order issues and suggesting alternatives for ERP systems. Likewise, Noack et al. (2011) presented an online simulation model prototype for a semiconductor wafer fabs manufacturing. By capturing real-time data from a real system, experimental results highlight the feasibility to continuously update the simulation model in real-time. By using the updated model, short-term alternatives can be checked quickly.

Furthermore, adaptive scheduling and control issue from dynamic manufacturing systems (such as remanufacturing) have also been researched with the support of a symbiotic simulation modelling technique. For example, Kück et al. (2016) designed a data-driven SBO method to schedule complex stochastic and dynamic manufacturing systems. Using a semiconductor manufacturing facility as a case study, real-time data coupled with the simulation model promotes the capability to find better dispatching rules, improving production scheduling and system performance. Similarly, Fanchao et al. (2009) presented a symbiotic simulation control system for proactive inventory management analysis from a lubricant additive industry. Using a symbiotic simulation framework, it was possible to run reactive analysis to find solutions to low finished product fill rates.

Traceability and real-time monitoring of the remanufacturing systems have also been investigated with the support of Cyber-Physical System (CPS), Internet of Things (IoT) and other related ICT technologies. Wang \& Wang (2018) proposed a CPS-based system architecture to manage the remanufacturing of Waste Electrical and Electronic Equipment (WEEE). Running under a laboratory environment, the designed system architecture could manage the product design, product status, logistics, and recovery routines in a unified information flow. Likewise, Sharper et al. (2018) employed CPS monitoring technologies on the recovery of WEEE products. They demonstrated how remanufacturing decision-making could be benefited from real-time tracking of assets and used product status. A case study at a UK company providing a recovery service for mobile and other Information Technology (IT) assets reported a substantial growth on throughput and substantial cost reduction. Zhang et al. (2018) also employed IoT to track real-time assets and the status of used products in an automobile engine remanufacture plants. Using the data captured from the shop-floor, a real-time scheduling method and a Pareto-based optimizer were developed to reduce production costs and energy consumption considerably. 
Despite the valuable contribution from the above-mentioned studies, some important issues remain unclear. Most of the previous modelling and simulation work for decision support in remanufacturing has focused on business model design issues alone, with little or no consideration of uncertain and unforeseen circumstances that arise during the contract execution period (variability in: customer's demand, product RC, recovery routine, plant capability, etc.). Even though those studies have been recognised as making an important contribution to the redefining of product recovery policies, modelling and simulation to manage remanufacture service contract execution has not received sufficient attention. Based on modelling and simulation assistance, companies can better understand product recovery issues in two ways: (1) to introduce the remanufacture concept in a manufacturing company, or (2) to evaluate an existing remanufacturing process (Slotina and Dace 2016). Current literature on remanufacturing process modelling and the simulation approach (Golinska-Dawson and Pawlewski 2018) and contract analysis to support remanufacturers (Ghosh et al. 2018) are quite limited. Moreover, Smith-Gillespie et al. (2014) reckoned remanufacturing is still relatively immature and is plagued by complexity and uncertainty that should be further investigated. Therefore, the application of modelling and simulation methods with real-time data connection in remanufacturing seems to be missing or not completely understood yet.

The development of a best practices system and tools can help remanufacturing companies to meet desired strategic goals and outcomes. Furthermore, modelling and simulation tools must offer supplementary assistance, enabling critical operational decisions in a product recovery business model (Galbreth 2006) with real-time monitoring technology support (Sharpe, et al. 2018). Through modelling and simulation, service providers must mimic what happens in a real system, bringing to the virtual environment those complexities and uncertainties occurring in the service phase (Tjahjono, Teixeira and Alfaro 2013). In aiming to enhance credibility of the simulation-based experiment results, the simulation model must progress over time as much as the business model evolves and grows (Low et al. 2007). To do so, components, parameters, and behaviours from the simulation model must periodically be revised using real-time data obtained from the physical system.

Closing the gap between the simulation model and the remanufacturing system, the product recovery industry can better match customers' demands to the production capacity. Similarly, risks and doubts about clause modifications in running contracts can also be checked through cost-benefit analysis (CBA). Monitoring the changing business environment and manage 
disturbances in real-time with online simulation models can, undoubtedly, contribute to the better management of complex dynamic systems (Wang 2010). However, industrial cases and practical studies are lacking in showing how operational decision support can be done in a remanufacturing system (Poles 2013). Real data and practitioner feedback obtained from the remanufacturing industry are fundamental for the effective use of modelling and simulation tools (Mutingi and Mhlanga 2013; Lehr, Thun and Milling 2013).

\section{RESEARCH METHOD}

Considering the aim of the paper and taking into account previous work and contributions in the related area, our research to a large extent follows the design science research method (Von Alan et al. 2004) proposed for information systems (Peffers et al. 2007). In this research methodology, the knowledge obtained from professionals of the discipline in question is used to design a scientific solution, taking into account observation and field problems. Following the procedures from design science research methodology, this study was conducted through six steps (Peffers et al. 2007):

1. Problem identification and motivation;

2. Define objectives for a solution;

3. Design and development;

4. Demonstration;

5. Evaluation;

6. Communication.

Problem identification and motivation relies on a deep understanding of the remanufacturing system, its characteristics and particularities. It is fundamental to describe the desired organisational information process capability and its relationship with the presented and desired organisational situation (March and Storey 2008). To do so, a substantial effort was placed on gathering information related to the remanufacturing of power transformers. Previous service contracts, technical recommendations, and business reports obtained were collated to increase the body of knowledge. Some additional investigation through interviews with managers, industrial engineers, and shop floor workers were also included in the research. Those activities resulted in a detailed mapping of all remanufacturing system operations, processes, and routines. 
As the objective of design science research for information systems is to develop technologybased solutions relevant to the business problems (Hevner and Chatterjee 2010), the performance metrics relevant to the power transformer remanufacturing system were formulated. Previous service contracts and research papers were again revisited in order to find more specific Key Performance Indicators (KPIs). Results obtained suggest that performance measures must reflect customer expectations and service provider capabilities. In particular, performance measures in power transformer remanufacturing usually serve three different purposes: (1) to formulate business strategy; (2) to quantify service contract outcomes; and (3) to evaluate remanufacture process performance.

Design science research must produce a viable artefact in the form of a construct, a model, a method, or an instantiation (Hevner et al. 2008). In the design and development stage, our artefact is the proposed symbiotic simulation framework and the simulation model. The symbiotic simulation framework provides an effective way to build symbiotic simulation models containing the operational decision support for the remanufacturing companies. Furthermore, a detailed explanation about the symbiotic simulation modules and components were also considered to better understand how a symbiotic simulation model works. The symbiotic simulation model allows a virtual emulation of remanufacturing operations using acquired data to match the virtual and real systems, making simulation outcomes more credible.

After the development of the simulation model, simulation experimentation was carried out following the rules proposed by Peffers et al. (2007). At this stage, some potential issues and changes commonly found within the remanufacturing system were identified. During the design of experiments, various scenarios encountered in power transformer remanufacturing were observed. These scenarios are established by means of 'what-if' questions. Depending on the specific analysis required, the simulation run time can be adjusted.

Evaluation and communication are important in design science research methodology (Von Alan et al. 2004). At the evaluation stage, the artefact must be evaluated to demonstrate its worthiness using criteria such as validity, utility, quality, and efficacy (Gregor and Hevner 2013). During this stage, the researchers will examine the simulation results aiming to answer those 'what-if' questions from the remanufacturing service contract analysis. Any conclusion about customer's requirements and service delivery must be sustained by means of a performance evaluation. This stage requires particular caution and attention from the service 
provider, because the simulation model is still a representation of a real system with some assumptions, which may lead to deviation between practical and simulated results.

\section{SYSTEM DEVELOPMENT}

\subsection{Description of the remanufacturing system}

An industrial case study of power transformer remanufacturing is presented here to illustrate how SSS can support contract remanufacturers in managing service contracts planning and execution. The selected company is a third party that offers contracts of maintenance, repair, and overhaul services of transformers. When the service contract is running, used transformers will be taken back by the service providers (contract remanufacturers). The contract terms will determine the number of transformers per month. Though some repair activities can be run on customers' sites, major repairs, such as winding or oil insulation replacement, would need to be done at the transformer factory, considering the availability of space and equipment (Lorin et al. 2014); a storage area should therefore be available to receive used transformers. This area is usually prepared in such a way that avoids soil and groundwater contamination. Disassembly and inspection are the two important activities for evaluation (i.e. parts for recovery or replacement) (Gharbi, Pellerin and Sadr 2008).

Each power transformer requires an individual remanufacturing plan. To do this, the engineering team obtains additional used product information (such as, winding block's dimension, effective area, potency, etc.) for design purposes. Still in the design stage, the service provider verifies the technical feasibility to repower the aged transformer. A supplementary budget can be negotiated with the customer to cover additional expenses and material needed. Once the design stage is finished, a work order can be generated. It is important to mention that each work order includes the entire design specification and technical requirements from the remanufacturing plan.

Once the design plan is ready, a work order is dispatched to start the remanufacture plan. The aged tank is sent to the housing line, whilst the winding block goes to the core line. The housing line, in turn, includes a set of sequential activities to reform the tank (i.e., washing, preparing, painting, and accessory assembling). At the washing station, the tank is washed to remove oil residues. At the preparing stage, repair operations (such as sanding, welding, sandblasting, etc.) 
are executed according to a predetermined remanufacture plan. Thereafter, the tank receives a primer paint layer (for corrosion protection) and a final paint layer. In the last housing station, the tank receives additional items (i.e., such as clamp, flanges, screws, etc.) for the final assembly operation.

Winding block damaged components are manufactured at the core line. Likewise, a set of sequential activities (i.e., material preparation, low-voltage (LV) winding, high-voltage (HV) winding, mounting, testing, and drying) are needed to repair core components. Materials to insulate core windings are firstly prepared. These materials are subsequently used to produce the LV and HV windings. They are assembled at the winding block and connected through a welding operation. Then the transformer turns ratio (TTR) test will be carried out to check if the number of transformer's LV and HV windings match the intended specification. If the winding block is approved, it will be forwarded to the warming house; otherwise, it needs to be reworked.

The warming house is a critical process for the remanufacturing process. It removes the moisture from the insulation materials improving the winding block's dielectric properties. It plays an important role in the lifetime of the transformer, which is typically defined by a lifetime of cellulose insulation (Frimpong, Oommen and Asano 2011). According to the available warming house space, one labourer fills it with queued winding blocks; they should remain from 48 to 72 hours in it in order to ensure complete moisture removal. Once the warming process has finished, the winding blocks and tanks are joined at assembly line and final test. Thereafter, transformers are sent to vacuum chamber to be filled out with treated oil insulation. At the last stage, the transformer is tested and once it is approved it can be sent to the warehouse. Figure 1 shows the power transformers remanufacturing system. 


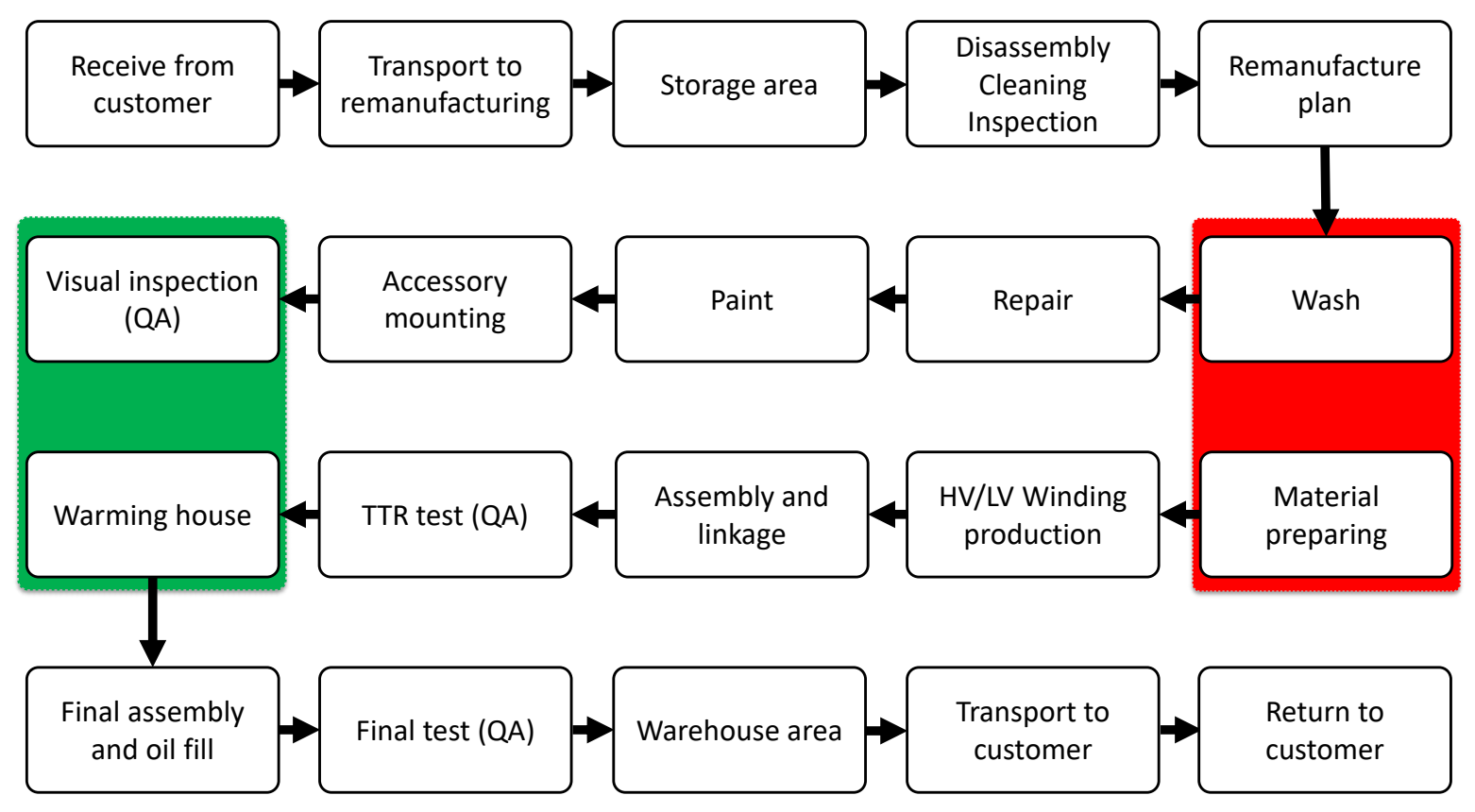

Figure 1: Power transformer remanufacturing system

\subsection{Performance measures}

In order to better understand the business implications, production outputs and potential risks arising during the service contract execution, a performance measure is required. The condition of the used product is an important factor in remanufacturing, requiring KPIs to cover the range of core-related activity (Graham et al. 2015). Within a power transformer remanufacture, Remanufacturing Cost (RC) depends on the damage found on the individual used product (i.e. power transformer). As a consequence, the $\mathrm{RC}$ is made up of various types of additional reprocessing operations. After calculating the RC, the service provider must recover or scrap the power transformer according to the cost of a new unit. An acceptable product RC is normally between $45 \%$ and $65 \%$ of the price of a comparable new product (Statham 2006; Lund and Hauser 2010). In order to determine the economic benefits associated with the product recovery, the service provider can calculate the RC for individual units as follows:

$$
R C=\left(\sum_{i=0}^{n} R I_{i}\right) \times P R \times C I
$$

The first term is the sum of the $i$ th reprocessing operation index (RI). A reprocessing operation considers a financial cost index related to each individual product recovery routine. RC is also a function of transformer power rating (PR) and conversion index (CI). A CI is established and 
updated in agreement between customer and service provider. From a particular service contract, the total remanufacturing cost (TRC) can be obtained by:

$$
T R C=\sum_{i=0}^{n} R C_{i}
$$

TRC is a crucial performance indicator for the service provider. It denotes an indication of potential revenue gained from the service contract. Likewise, penalties are also important metrics monitored by the service provider. Penalty is a contractual term where the service provider agrees to reimburse the customer whenever it fails to fulfil its promises. In the transformer remanufacturing business model, customers may penalise the service providers due to the delay in withdrawal of transformers (WD) on service site or whenever they postpone the return of remanufactured transformers (RD) or from those under warranty (WR). The total penalty cost (TPC) incurred on the service contract can therefore be calculated using the following formula:

$$
T P C=\left(\sum_{i=0}^{n} W D_{i} \times R C_{i}\right) I_{W D}+\left(\sum_{j=0}^{m} R D_{j} \times R C_{j}\right) I_{R D}+\left(\sum_{k=0}^{p} W R_{k} \times R C_{k}\right) I_{W R}
$$

Where $I_{W D}, I_{R D}$ and $I_{W R}$ are WD, RD and WR penalty indices, respectively. Those indices are predefined at service contract design stage. The remanufacturing industry often uses an on-time delivery (OTD) as a performance indicator to measure customer experience and satisfaction. OTD can be defined as the percentage of time that remanufacturing delivers a completed transformer according to a schedule that was promised to the electrical distributor. In fact, OTD is a fundamental aspect, among many others, for the success of product and business (Karim et al. 2010). It helps service providers determine how efficient they are in meeting their customers' deadlines. Furthermore, some customers insert contractual clauses to break a given service contract based on OTD value. In the transformer remanufacture industry, OTD is calculated as:

$$
O T D=\frac{1}{T D} \sum T D O
$$


Where $T D, T D O$ is the total transformer returned and total transformer returned on time respectively. Service providers also need to monitor the production performance during the execution of the SCs. Often, lower production throughputs delay a transformer's return. For this reason, some production and operations management, such as yield, throughput, operational availability, capacity utilisation, etc., are used. In the energy product recovery industry, yield (YD) is defined as a percentage of power transformers which are reformed successfully, first time without rework. Operational availability (OA), capacity utilisation (CU), and overall process effectiveness (OPE) are also some important KPIs from the remanufacturing plant. In the remanufacture business model, those performance measures are calculated as:

$$
\begin{gathered}
Y D=\frac{1}{T R T}\left(\sum_{i=0}^{n} A T_{i}-\sum_{j=0}^{m} F T_{j}\right) \\
C U=\frac{1}{M P T}\left(\sum_{i=0}^{n} A T_{i}\right) \\
O A=\frac{\min \left(M T B F_{1}, M T B F_{2}, \cdots, M T B F_{n}\right)}{\min \left(M T B F_{1}, M T B F_{2}, \cdots, M T B F_{n}\right)+\max \left(M T T R_{1}, M T T R_{2}, \cdots, M T T R_{n}\right)} \\
O P E=C U \times O A \times Y D
\end{gathered}
$$

Where:

TRT = Amount of power transformers remanufactured;

AT $=$ Approved transformer in final test;

FT $\quad=$ Failed transformer in final test;

MPT = Maximum possible power transformer remanufactured;

$\mathrm{MTBF}=$ Mean time between failure from a reprocessing workstation;

$\mathrm{MTTR}=$ Mean time to repair from a reprocessing workstation.

\subsection{Symbiotic simulation}

In symbiotic simulation, customer requirements and real-time data are grouped and inserted into a simulation model. Following alternative scenarios, service providers can validate business 
needs beforehand so as to achieve improved operational outcomes. Using a particular mechanism to convert acquired data into information, the simulation model can be synchronised with the physical system, both becoming like a cyber-physical entity. As a result, disturbances and potential risks can be anticipated by creating "what-if" scenarios, adjusting them as soon as the conditions change. Besides, current state and recent history from physical systems will be immediately amended in the simulation model (Wynn et al. 2008). Figure 2 shows the proposed symbiotic simulation framework for a remanufacturing system.

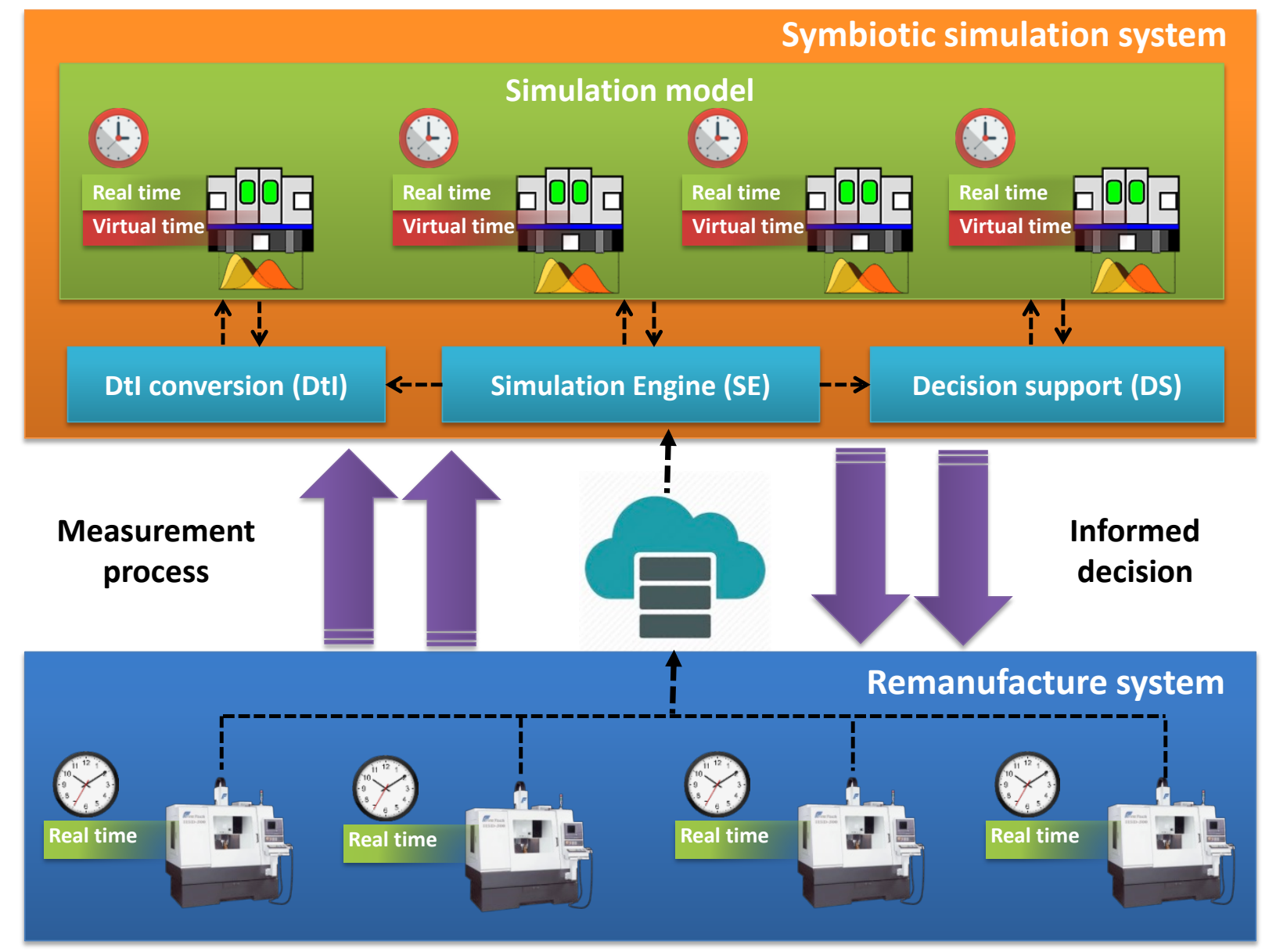

Figure 2: Symbiotic simulation system framework

The measurement process is of vital importance for an SSS. Based on industrial automation technology (such as sensor, PLC, OPC, etc.) previously mapped process variables are tagged, grouped, and retrieved from the remanufacturing process. Those variables may include whatever parameters are necessary to emulate asset state and behaviour (such as equipment condition, machine cycle time, transformer reprocessing stage, available storage area, etc.). Timed or event driven data should be considered during the data acquisition system design. Likewise, different 
operating range or acquisition rate may also be required to implement the measurement process. Gauged data are then stored in a database for future analysis and use.

Data to Information (DtI) conversion can be considered as one of the most important modules for an SSS. Basically, it can entail pre-processing and learning functionalities to turn measured data into useful information. Raw data are commonly unorganised and rarely utilised without previous preparation. Data pre-processing enables drastically improving data utilisation. Furthermore, it provides an effective way to extract meaningful knowledge from given set of data (Famili et al. 1997). Filtering, conversion, isolation, and linearization are some data management and optimisation techniques commonly used to organise data acquired from manufacturing plant. Once acquired data are processed, organised, and structured in a given context, they become useful information, enabling the update of simulation components. Sometimes the data pre-processing stage alone cannot source sufficient information for the simulation model, thus requiring the inclusion of a learning mechanism.

Learning mechanism (LM) is another feature commonly included in the DtI conversion module. In an SSS, LM is related to a certain kind of pattern recognition and machine learning methods employed to embed additional knowledge and to review the original conditions of the simulation model. For instance, with an LM, asset condition monitoring data can be propagated until asset virtual representation; also the parameters and shape of probability distributions can be fitted to better represent stochastic behaviour from the remanufacturing system. Bayesian machine learning, maximum likelihood, support vector machine, and Kalman filtering have been often employed to extract important characteristics from physical systems. Considering the computational effort required by learning techniques, a DtI conversion module must run concurrently with the simulation model.

The simulation engine (SE) is another fundamental component of symbiotic simulation. Basically, it manages the uploading of information and the appropriate execution of a simulation model. Likewise, an SE controls the dynamic upgrade of the simulation model by adding or removing components and their linkage whenever necessary. The SE kernel assigns different threads to execute data acquisition and DtI conversion (real-time) and simulation run (virtualtime) activities. As a consequence, the simulation model can run faster or roll back over virtual time without disturbance from the measurement process and DtI as a daemon (i.e. a computer programme that runs as a background process). As soon as the user starts the simulation 
execution, the SE notifies the DtI conversion and decision support module to invoke initialisation functions. At this time, the execution of the simulation model is momentarily interrupted for synchronisation purposes, avoiding false alarms and inconsistencies.

The SE entails both a completion horizon and execution mode parameters in order to set the simulation mode execution. The former highlights the amount of virtual time available for the simulation engine to run, whilst the latter states the data acquisition and synchronisation strategy. A completion horizon can be set according to the desired stop condition (i.e., absolute virtual time, jobs completed, or performance criteria). In addition, the execution mode parameter enables the DtI conversion module to forward information continuously or in one shot to the simulation model. In the continuous execution mode, SE is configured to listener DtI notifications with new available input data. Thus, SE interrupts the simulation execution momentarily to resynchronise the simulation model. The inconvenience of this execution mode resides in the difficulty return the simulation model to the initial stage again. In contrast, the one-shot execution mode allows the service provider team to test numerous what-if scenarios and simulation experiments blocking resynchronisation event interruption whilst simulation model is running. To avoid inconsistent results, the SE was made unable to roll the simulation model back from the current time position loading the latest input data when simulation model initialises. Figure 3 shows symbiotic simulation system configuration and execution. 

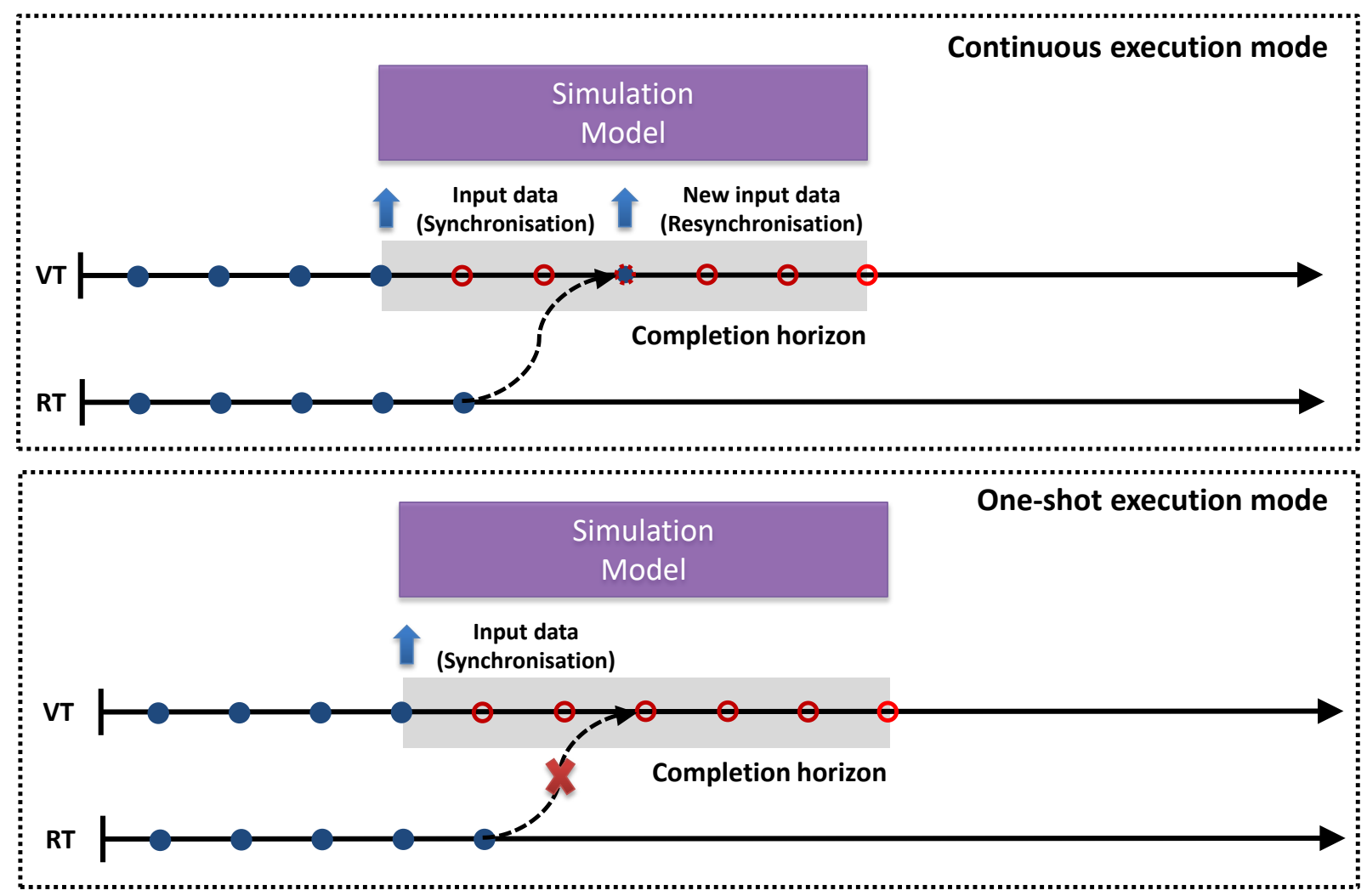

Legend: VT - Virtual time; $\mathbf{R T}$ - Real time

Figure 3: Symbiotic simulation system configuration and execution.

\subsection{Simulation model}

The simulation model is based on a detailed study of the service provider's business operations. In addition, previous SCs and recommended power transformer remanufacture procedures were also considered in the research scheme. Observation, interview, and probing were carried out with managers, shop floor workers, and directors to obtain more specific information about production, supply chain, and transport logistics. Also, previous service contracts and a sixmonth production report from third party company were used to design simulation model and to determine input data, random variables and probability distributions. In summary, a symbiotic simulation model for power transformer remanufacture is made up of the following modules: commercial analysis, transport logistics, remanufacturing, and cost-benefit analysis.

Commercial analysis encompasses conditions and terms established in the service contracts. It also embeds customer agreements and performance levels defined at the service design stage. Whenever a customer demands a revision or modification to a given running contract, the service provider can, in turn, retrieve and test contractual conditions modification by executing 
simulation experiments, considering the current state of the shop floor. Commercial input data (i.e., expedition time, delivery time, warranty return, penalties, etc.) were obtained previous revisited SCs. Uncertainty on used transformer batch generation is emulating by using uniform distribution. In this case, the simulation model assumes that each type of power transformer has the same probability of being selected to be remanufactured.

Transport logistics is also crucial for the success of this type of business model. Power transformers with high damage extension, weight, and size usually demand additional effort and time from the transport team, delaying receiving and returning to the customer. Due to the lack of empirical data, uncertainty in time to load/unload were emulated by using triangular distribution. Additionally, providers have limited resources used for various SCs running at the same time, thus particular attention needs to be paid to the logistics aspects (such as truck availability, truck storage space, trip distance, etc.). Inputs for transport logistics comprise: time to load, trip time, time to unload, available trucks, etc., with storage and warehouse available area also being included. In particular, storage area evaluation is mandatory to set up new business demands because remanufacturing companies aim to understand whether there will be enough space to receive end-of-life transformers.

The remanufacturing module contains components to emulate remanufacture operations. It also includes a load information and simulation engine components (see Figure 4) for controlling the execution of the simulation model. The sLoadInformation element is a visual representation of a DtI conversion module within the symbiotic simulation module. It updates simulation model components' parameters using the latest DtI outcomes. Each event synchronisation occurrence is represented by blinking antenna above the symbiotic simulation model components. Additionally, the sSimulationEngine embeds those functionalities abovementioned in section 4.3.2. Data for production analysis contains machine cycle time, number of breakdowns, number of labourers, power transformer entity, etc. Uncertainties in remanufacturing plant includes: machine mean time to failure (MTTF), mean time to repair (MTTR), TTR test rejection and final test rejection were emulated by using exponential, triangular, uniform and uniform probability distributions respectively.

Cost-benefit analysis (CBA) relies on contractual requirements and predefined business goals. Based on CBA outcomes, managers and industrial engineers can gauge the performance of a given service contract. Furthermore, CBA can demonstrate potential revenue and loss associated 
with desired contract terms and conditions. It can also supply reliable assistance in evaluating contract extension or renegotiation. Essentially, the CBA dimension embeds those KPIs established in section 4.2. Moreover, it calculates cumulative profit based on transformer RC. Whenever an available expedition, delivery, or warranty period is exceeded, CBA will subtract a penalty cost from the contract revenues. Input data for CBA dimensions are loaded from a commercial analysis module and SCs. Again, output data include the business KPIs from section 4.2. Figure 4 shows a symbiotic simulation model for power transformer remanufacturing.

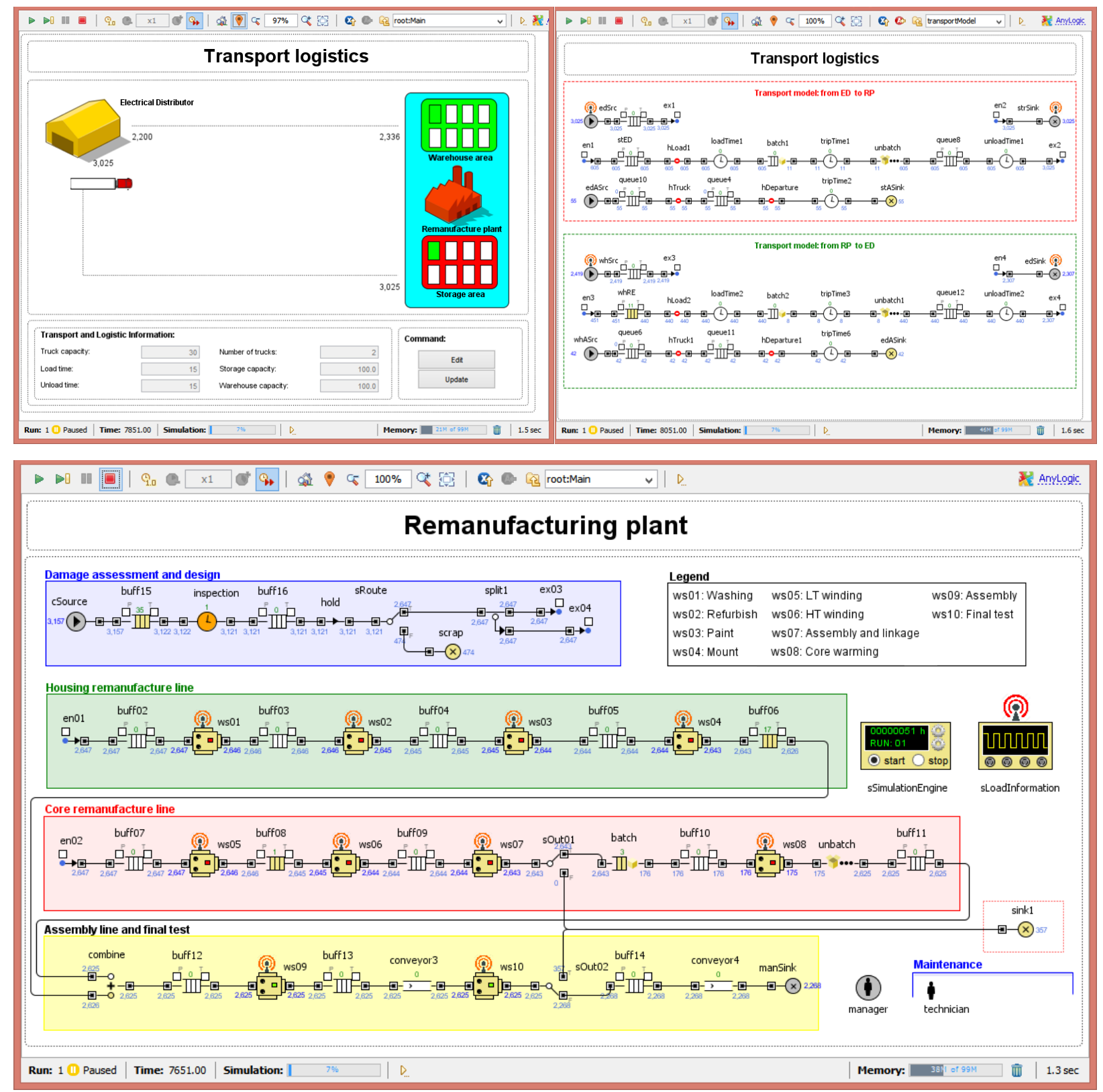

Figure 4: Symbiotic simulation model for power transformer remanufacturing 


\section{EXPERIMENTATION}

Two experiments were carried out to assess the performance of the service contracts. The chosen scenarios highlighted the main issues and circumstances faced by electrical distributors and the remanufacturer during the service contract execution, thus acted as the underpinning for further investigations. The customers' on-site repair and preventive maintenance are outside the scope of this research and, therefore, were not considered.

\subsection{Scenario 1: Plant processing capacity variation}

Plant processing capacity variation is a typical analysis required by the service provider. Undoubtedly, it can influence business outcomes and the service achieved during contract execution. Operational and environmental conditions that cannot be predicted with certainty modify planned reprocessing performance; for instance, if a machine fails later than expected, production capability should, in turn, increase. Additional production capacity and improvements are often used to negotiate new SCs. Notwithstanding, reduction in machines' mean time to failure (MTTF) should caution the service provider to potential delays in returns thus risking profits and customer satisfaction. In summary, the product recovery industry is continuously facing challengers in balancing positive and negative impacts due to variation in plant processing capacity.

The first experimental scenario comprises five SCs. SC conditions entail predefined amounts of customer core demand and supply, while the remanufacture is a supplier of spare parts. Investment in scrapped core acquisition is also needed for transformer disposal and recycling purposes. Each contract is related to a particular electrical distributor placed in different locations. The power transformer type is randomly selected according to its power rating. Monthly average refers to the average number of power transformers to be remanufactured each month. Expedition time, delivery time, and warranty return are agreed deadlines to take and to return renewed power transformers. Penalties indices are also included on each service contract reducing prospective remanufacturing gains. The other input data were obtained from selected remanufacturing firm. Table 2 highlights the input data for experimental scenario 1 .

Table 2: Input data for experimental scenario 1 


\begin{tabular}{|c|c|c|c|c|c|}
\hline & SC01 & SC02 & $\mathrm{SC03}$ & SC04 & SC05 \\
\hline Contract duration (in years) & 08 & 10 & 15 & 10 & 12 \\
\hline Power transformer type (KVA) & $1 \mathrm{~A}, 1 \mathrm{~B}, 1 \mathrm{C}, 1 \mathrm{D}$ & $1 \mathrm{~A}, 1 \mathrm{C}, 3 \mathrm{D}, 3 \mathrm{E}$ & $3 \mathrm{~A}, 1 \mathrm{~B}, 1 \mathrm{D}, 3 \mathrm{E}$ & $3 \mathrm{C}, 1 \mathrm{D}, 3 \mathrm{D}, 3 \mathrm{E}$ & $1 \mathrm{~A}, 3 \mathrm{~B}, 1 \mathrm{D}, 3 \mathrm{E}$ \\
\hline Monthly average (unit) & 35 & 40 & 30 & 50 & 40 \\
\hline Withdrawal time (in days) & 05 & 07 & 05 & 10 & 15 \\
\hline Return time (in days) & 45 & 40 & 60 & 45 & 60 \\
\hline Warranty return (in days) & 15 & 20 & 15 & 30 & 20 \\
\hline Penalty indices (WD,RD,WR) (\%) & $10,10,40$ & $10,15,45$ & $05,20,50$ & $10,15,35$ & $15,15,45$ \\
\hline Distance time (in days) & 1 & 3 & 2 & 1 & 3 \\
\hline \multicolumn{6}{|l|}{ Transport logistics } \\
\hline Available trucks & \multicolumn{5}{|l|}{2} \\
\hline Truck storage space $\left(\mathrm{m}^{2}\right)$ & \multicolumn{5}{|l|}{33.6} \\
\hline Load truck time (min) & \multicolumn{5}{|c|}{$=$ triangular $(15)$} \\
\hline Unload truck time (min) & \multicolumn{5}{|c|}{$=$ triangular $(15)$} \\
\hline Storage area $\left(\mathrm{m}^{2}\right)$ & \multicolumn{5}{|l|}{1,600} \\
\hline Warehouse area $\left(\mathrm{m}^{2}\right)$ & \multicolumn{5}{|l|}{1,200} \\
\hline \multicolumn{6}{|l|}{ Remanufacturing } \\
\hline Machine cycle time (h) & \multicolumn{5}{|c|}{$\begin{array}{l}\text { ws } 01=0.537 ; \mathrm{ws} 02=0.541 ; \mathrm{ws} 03=0.555 ; \mathrm{ws} 04=0.635 ; \mathrm{ws} 05=0.518 ; \\
\text { ws } 06=0.473 ; \mathrm{ws} 07=0.497 ; \mathrm{ws} 08=0.513 ; \mathrm{ws} 09=0.635 ; \mathrm{ws} 10=0.635\end{array}$} \\
\hline $\operatorname{MTBF}(\mathrm{h})=\operatorname{exponential}(\mathrm{x})$ & \multicolumn{5}{|c|}{$\mathrm{ws} 01=3,100 ; \mathrm{ws} 02=1,800 ; \mathrm{ws} 03=4,100 ; \mathrm{ws} 04=\mathrm{N} / \mathrm{D} ; \mathrm{ws} 05=3,800$} \\
\hline $\operatorname{MTTR}(\mathrm{h})=$ triangular $(\mathrm{x})$ & \multicolumn{5}{|c|}{$\mathrm{ws} 01=40 ; \mathrm{ws} 02=52 ; \mathrm{ws} 03=35 ; \mathrm{ws} 04=\mathrm{N} / \mathrm{D} ; \mathrm{ws} 05=60 ; \mathrm{ws} 06=32$} \\
\hline TTR test rejection $(\%)$ & \multicolumn{5}{|c|}{$=$ uniform ()$<05$} \\
\hline Final test rejection $(\%)$ & \multicolumn{5}{|c|}{$=$ uniform ()$<12$} \\
\hline
\end{tabular}

Legend: 1A - single phase 5KVA; 1B - single phase 10KVA; 1C - single phase 25KVA; 1D - single phase 30KVA; 3A - three phase $15 \mathrm{KVA} ; 3 \mathbf{B}$ - three phase $30 \mathrm{KVA}$; 3C - three phase $112.5 \mathrm{KVA}$; 3D - three phase $225 \mathrm{KVA}$; $3 \mathbf{E}$ - three phase $300 \mathrm{KVA}$;

Aiming to understand the impact from plant capacity variation, a potential reduction (15\%) in the lifespan of the assets was inserted after the third year. For comparative analysis purposes, cost-benefit results were collected before and after three years of execution of SCs. With assets' lifetime variation, some potential questions that should be answered are: (1) Can asset lifetime variation significantly affect production and service contract performances? (2) Can service providers take a new service contract considering the current remanufacture capability? Results from experimental scenario 1 are shown in Figure 5 and Table 3.

Figure 5: Results obtained from experimental scenario 1 


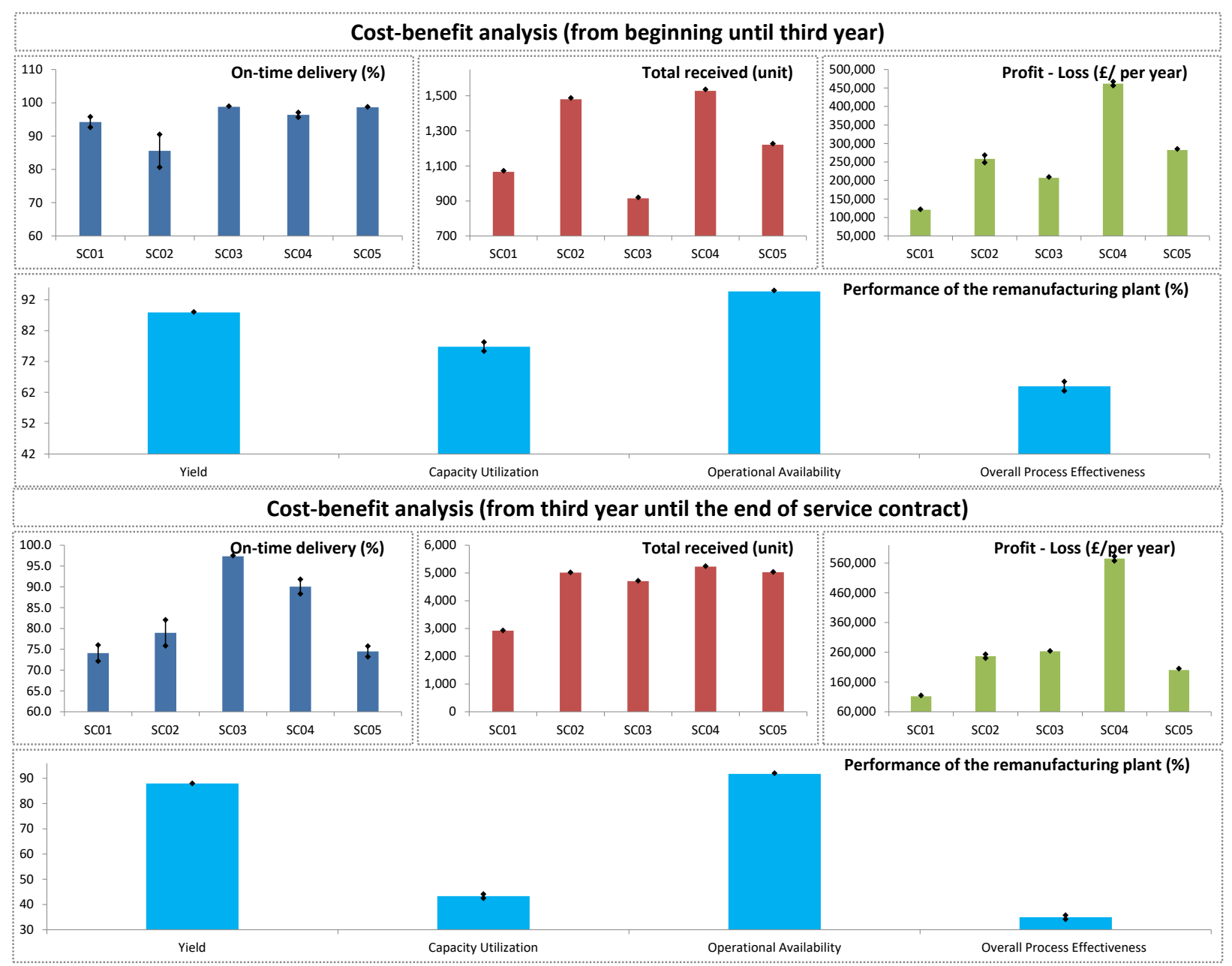

Table 3: Confidence interval analysis from experimental scenario 1

\begin{tabular}{|c|c|c|c|c|c|c|}
\hline \multicolumn{7}{|c|}{ Cost-benefit analysis (from beginning until third year) } \\
\hline \multirow[t]{2}{*}{ Service Contract } & \multicolumn{2}{|c|}{ On-time delivery (\%) } & \multicolumn{2}{|c|}{ Total received (unit) } & \multicolumn{2}{|c|}{ Profits-Loss (f/per year) } \\
\hline & Mean & $\overline{\text { SD }}$ & Mean & $\overline{\text { SD }}$ & Mean & SD \\
\hline SC01 & 94.2 & $( \pm 1.6)$ & 1,066 & $( \pm 7)$ & 121,041 & $( \pm 1,306)$ \\
\hline $\mathrm{SC} 02$ & 85.6 & $( \pm 4.9)$ & 1,480 & $( \pm 7)$ & 258,539 & $( \pm 10,046)$ \\
\hline $\mathrm{SC} 03$ & 98.8 & $( \pm 0.2)$ & 915 & $( \pm 6)$ & 207,130 & $( \pm 2,190)$ \\
\hline $\mathrm{SC} 04$ & 96.4 & $( \pm 0.7)$ & 1,528 & $( \pm 8)$ & 461,848 & $( \pm 5,339)$ \\
\hline $\mathrm{SC} 05$ & 98.6 & $( \pm 0.1)$ & 1,221 & $( \pm 7)$ & 282,496 & $( \pm 2,821)$ \\
\hline \multicolumn{7}{|c|}{ Performance of the remanufacture plant } \\
\hline & & & Mean & SD & & \\
\hline & & Yield (\%) & 87.9 & $( \pm 0.1)$ & & \\
\hline \multicolumn{3}{|c|}{ Capacity utilisation (\%) } & 76.8 & $( \pm 1.5)$ & & \\
\hline \multicolumn{3}{|c|}{ Operational availability (\%) } & 94.7 & $( \pm 0.3)$ & & \\
\hline \multicolumn{3}{|c|}{ Overall process effectiveness (\%) } & 63.9 & $( \pm 1.4)$ & & \\
\hline
\end{tabular}




\begin{tabular}{|c|c|c|c|c|c|c|}
\hline \multicolumn{7}{|c|}{ Cost-benefit analysis (from third year until the end of service contract) } \\
\hline \multirow[t]{2}{*}{ Service Contract } & \multicolumn{2}{|c|}{ On-time delivery (\%) } & \multicolumn{2}{|c|}{ Total received (unit) } & \multicolumn{2}{|c|}{ Profits-Loss (£/per year) } \\
\hline & Mean & SD & Mean & SD & Mean & SD \\
\hline $\mathrm{SC} 01$ & 74.1 & $( \pm 1.9)$ & 2,921 & $( \pm 8)$ & 112,190 & $( \pm 2,495)$ \\
\hline $\mathrm{SC} 02$ & 79.0 & $( \pm 3.1)$ & 5,015 & $( \pm 7)$ & 246,591 & $( \pm 6,365)$ \\
\hline $\mathrm{SC} 03$ & 97.3 & $( \pm 0.2)$ & 4,707 & $( \pm 10)$ & 263,331 & $( \pm 876)$ \\
\hline $\mathrm{SC} 04$ & 90.1 & $( \pm 1.7)$ & 5,231 & $( \pm 14)$ & 574,995 & $( \pm 7,675)$ \\
\hline $\mathrm{SC} 05$ & 74.5 & $( \pm 1.3)$ & 5,029 & $( \pm 11)$ & 200,203 & $( \pm 5,022)$ \\
\hline \multicolumn{7}{|c|}{ Performance of the remanufacture plant } \\
\hline & & & Mean & SD & & \\
\hline & & Yield (\%) & 87.9 & $( \pm 0.1)$ & & \\
\hline \multicolumn{3}{|c|}{ Capacity utilisation (\%) } & 43.3 & $( \pm 0.8)$ & & \\
\hline \multicolumn{3}{|c|}{ Operational availability (\%) } & 91.8 & $( \pm 0.3)$ & & \\
\hline \multicolumn{3}{|c|}{ Overall process effectiveness (\%) } & 34.9 & $( \pm 0.7)$ & & \\
\hline
\end{tabular}

Confidence Interval: 95 percent;

At the end of year 3, the service provider has achieved satisfactory results with profitable outcomes from the business model. On-time delivery (OTD) was above $85 \%$, highlighting a favourable outcome from the customer's viewpoint. In this kind of business model, the customer usually requires OTD greater than $85 \%$ otherwise the service contract could be cancelled. Capacity utilisation, operational availability, and overall process effectiveness indices $(76.8 \%$, $94.7 \%$, and $63.9 \%$ respectively) are close to the highest expected values. This suggests that the maximum capacity of the remanufacturing plant was achieved and no more SCs can be accepted for the time being. Furthermore, profit less loss per year obtained is within an acceptable margin limit, again, indicating a viable business model.

From year 3 until the end of the SCs, asset lifetime reduction considerably affected the plant. Besides, experimental results have shown that equipment MTTF variation can, in turn, reduce the capacity utilisation (from $76.8 \%$ to $43.3 \%$ ) and, slightly, the operational availability (from $94.7 \%$ to $91.8 \%$ ) of the remanufacture plant. It is worth mentioning that those reductions have also diminished the OPE (from $63.9 \%$ to $34.9 \%$ ) of the plant. Since OPE retains an overall perspective from the manufacturing environment (Dal, Tugwell and Greatbanks 2000), low OPE should be viewed with caution by always balancing production capacity against customers' demands. Yet, low on-time delivery (OTD) for service contracts 01,02 and $05(74.1 \%, 79.0 \%$ and $74.5 \%$ ) suggests a potential contract breakthrough. Finally, profit and loss per year from some SCs were reduced, indicating a potential loss of revenue. 
Experimental results highlighted that plant capacity variation can, in turn, affect the throughput of the remanufacture plant. With a shorter MTTF, assets require more stoppages for regular maintenance, thus diminishing the capacity utilisation. With numerous SCs running and less production time, inevitably service providers delay the return of power transformers. As a consequence, the penalties imposed reduce profit outcomes and customer satisfaction. With SSS support, service providers can bring, to the simulation model, current asset state and recent history. This closed loop between simulation model and physical systems can better provide indepth understand of potential risks and uncertainty coming from capacity variation, which occurs during the in-service phase.

\subsection{Scenario 2: Service contract terms modification}

Service contract modification is a typical situation where customers need to review contractual commitments. It is often required for long-term contracts, when the customers only have limited budget to replace scrapped transformers. Some requirements and contract inputs (such as delivery time, warranty return, etc.) must be revised in order to achieve a higher return rate. With a greater monthly average of transformer remanufactured, customers desire to minimise their inventory level. From the service providers' perspective, contract terms modification can be done solely with additional payment. Nevertheless, before accepting new terms, service providers should ensure that additional demand will not affect existing service contracts.

The second experiment also considers five SCs. Again, each contract is regarding particular customers' needs. After the end of the second year, customers from the second and fourth service contracts (SC02 and SC04) required a 20\% increase in monthly average of transformers being remanufactured. With supplementary returns of power transformers, some potential issues to be aware of are: (1) Can the service provider increase the transformer's return rate? (2) If yes, what is the highest allowable return rate without penalising other running service contracts? Table 4 summarises input data for Scenario 2.

Table 4: Input data for experimental scenario 2

\begin{tabular}{lccccc}
\hline Commercial analysis & \multicolumn{1}{c}{} & & & \\
\hline Parameter & SC01 & SC02 & SC03 & SC04 & SC05 \\
\cline { 2 - 6 } Contract duration (in years) & 12 & 08 & 10 & 15 & 05
\end{tabular}




\begin{tabular}{|c|c|c|c|c|c|}
\hline Power transformer type (KVA) & $1 \mathrm{C}, 1 \mathrm{D}, 3 \mathrm{D}, 3 \mathrm{E}$ & $3 \mathrm{~A}, 3 \mathrm{~B}, 3 \mathrm{C}, 3 \mathrm{E}$ & $1 \mathrm{D}, 3 \mathrm{~A}, 3 \mathrm{D}, 3 \mathrm{E}$ & $1 \mathrm{~A}, 1 \mathrm{C}, 1 \mathrm{D}, 3 \mathrm{E}$ & $1 \mathrm{D}, 3 \mathrm{~B}, 3 \mathrm{C}, 3 \mathrm{E}$ \\
\hline Withdrawal time (in days) & 10 & 12 & 07 & 10 & 07 \\
\hline Return time (in days) & 35 & 40 & 45 & 45 & 35 \\
\hline Warranty return time (in days) & 10 & 15 & 10 & 20 & 10 \\
\hline Monthly average (unit) & 55 & 45 & 30 & 50 & 55 \\
\hline Penalty indices (WD,RD,WR) (\%) & $10,10,40$ & $10,15,45$ & $05,20,50$ & $10,15,35$ & $15,15,45$ \\
\hline Distance time (in days) & 2 & 1 & 3 & 2 & 3 \\
\hline \multicolumn{6}{|l|}{ Transport logistics } \\
\hline Available trucks & \multicolumn{5}{|l|}{2} \\
\hline Truck storage space $\left(\mathrm{m}^{2}\right)$ & \multicolumn{5}{|l|}{33.6} \\
\hline Load truck time (min) & \multicolumn{5}{|c|}{$=$ triangular $(15)$} \\
\hline Unload truck time (min) & \multicolumn{5}{|c|}{$=$ triangular $(15)$} \\
\hline Storage capacity $\left(\mathrm{m}^{2}\right)$ & \multicolumn{5}{|c|}{1,600} \\
\hline Warehouse capacity $\left(\mathrm{m}^{2}\right)$ & \multicolumn{5}{|l|}{1,200} \\
\hline \multicolumn{6}{|l|}{ Remanufacturing } \\
\hline Machine cycle time (h) & \multicolumn{5}{|c|}{$\begin{array}{l}\text { ws } 01=0.537 ; \text { ws } 02=0.541 ; \text { ws } 03=0.555 ; \text { ws } 04=0.635 ; \text { ws } 05=0.518 \\
\text { ws } 06=0.473 ; \text { ws } 07=0.497 ; \text { ws } 08=0.513 ; \text { ws } 09=0.635 ; \text { ws } 10=0.635\end{array}$} \\
\hline MTBF $(\mathrm{h})=$ exponential $(\mathrm{x})$ & \multicolumn{5}{|c|}{$\begin{array}{l}\text { ws } 01=3,100 ; \text { ws } 02=1,800 ; \text { ws } 03=4,100 ; \text { ws } 04=\mathrm{N} / \mathrm{D} ; \mathrm{ws} 05=3,800 \\
\text { ws } 06=3,700 ; \mathrm{ws} 07=\mathrm{N} / \mathrm{D} ; \mathrm{ws} 08=1,300 ; \mathrm{ws} 09=4,800 ; \mathrm{ws} 10=\mathrm{N} / \mathrm{D}\end{array}$} \\
\hline MTTR $(\mathrm{h})=$ triangular $(\mathrm{x})$ & \multicolumn{5}{|c|}{$\begin{array}{l}\text { ws } 01=40 ; \text { ws } 02=52 ; \text { ws } 03=35 ; \text { ws } 04=\mathrm{N} / \mathrm{D} ; \text { ws } 05=60 ; \text { ws } 06=32 \text {; } \\
\text { ws } 07=\mathrm{N} / \mathrm{D} ; \text { ws } 08=72 ; \text { ws } 09=16 ; \text { ws } 10=\mathrm{N} / \mathrm{D} \text {. }\end{array}$} \\
\hline TTR test rejection (\%) & \multicolumn{5}{|c|}{$=$ uniform ()$<05$} \\
\hline Final test rejection $(\%)$ & \multicolumn{5}{|c|}{$=$ uniform ()$<12$} \\
\hline
\end{tabular}

Legend: 1A - single phase 5KVA; 1B - single phase 10KVA; 1C - single phase 25KVA; 1D - single phase 30KVA; 3A - three phase 15KVA; 3B - three phase 30KVA; 3C - three phase $112.5 \mathrm{KVA}$; 3D - three phase 225KVA; 3E - three phase 300KVA;

From the first two years, the service provider has achieved considerable outputs, suggesting a lucrative business return. OTD indices are greater than $85 \%$ indicating successful service contract execution with customer satisfaction. In particular, plant capacity utilisation (49.4\%) is far from the maximum allowance reprocessing limit, revealing an unused product recovery capability of the remanufacture plant. Moreover, low OPE index (40.9\%) also emphasises that increments on contractual deliverables can be done without negative consequences for other running SCs. In this sense, the first question is answered in the affirmative and, at first glance, it seems to be a reasonable idea to accept new customer demands. Figure 6 and Table 5 highlight results obtained from Scenario 2.

Figure 6: Results obtained from experimental scenario 2 


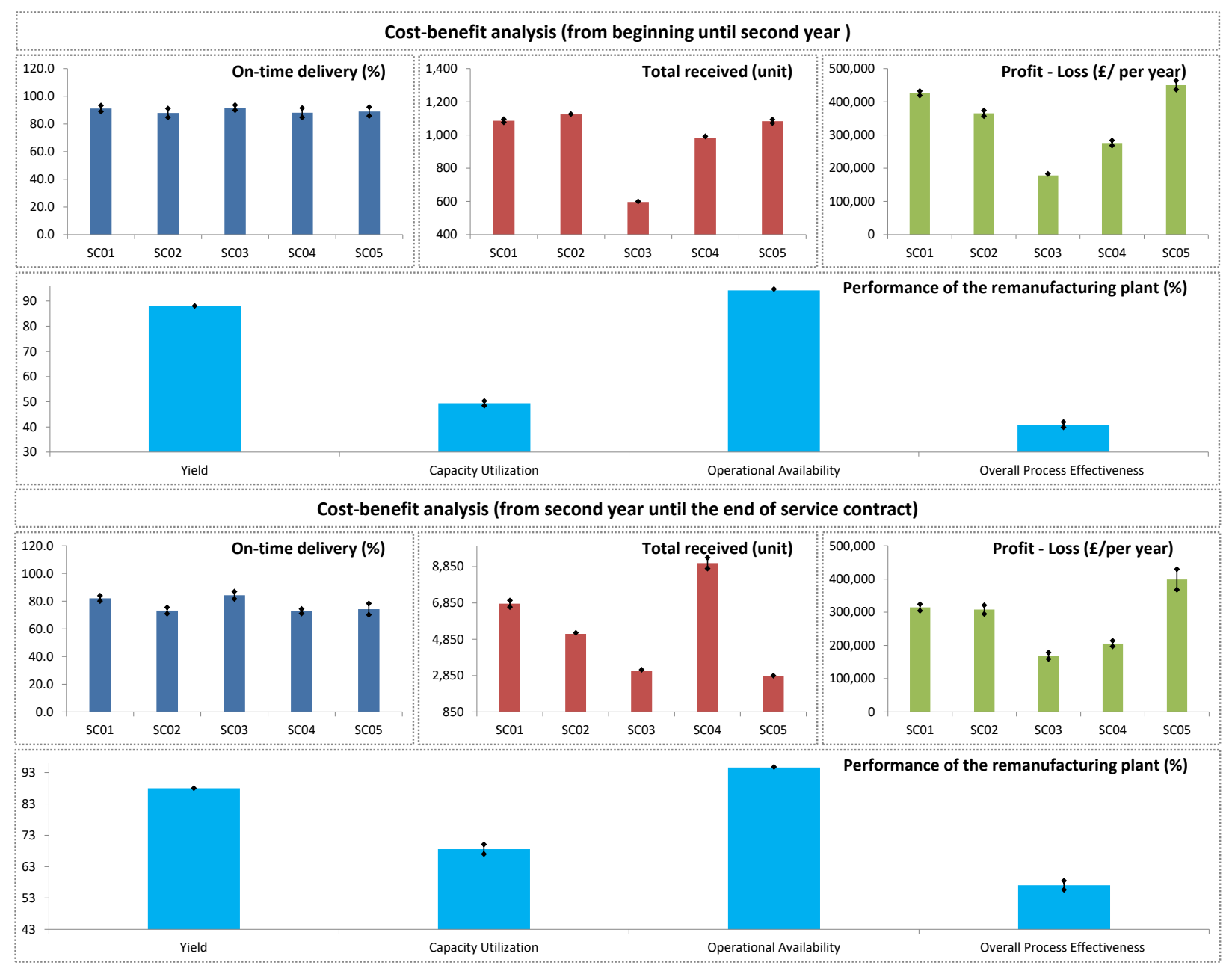

Table 5: Confidence interval analysis from experimental scenario 2

\begin{tabular}{|c|c|c|c|c|c|c|}
\hline \multicolumn{7}{|c|}{ Cost-benefit analysis (from beginning until second year) } \\
\hline \multirow[t]{2}{*}{ Service Contract } & \multicolumn{2}{|c|}{ On-time delivery (\%) } & \multicolumn{2}{|c|}{ Total received (unit) } & \multicolumn{2}{|c|}{ Profits-Loss (f/per year) } \\
\hline & Mean & SD & Mean & $\overline{\text { SD }}$ & Mean & SD \\
\hline SC01 & 91.1 & $( \pm 2.2)$ & 1,086 & $( \pm 9)$ & 425,553 & $( \pm 6,769)$ \\
\hline $\mathrm{SC} 02$ & 88.0 & $( \pm 3.2)$ & 1,124 & $( \pm 3)$ & 365,298 & $( \pm 8,465)$ \\
\hline $\mathrm{SC} 03$ & 91.7 & $( \pm 1.9)$ & 597 & $( \pm 4)$ & 178,447 & $( \pm 4,478)$ \\
\hline $\mathrm{SC} 04$ & 88.1 & $( \pm 3.4)$ & 984 & $( \pm 8)$ & 276,034 & $( \pm 7,742)$ \\
\hline $\mathrm{SC} 05$ & 89.0 & $( \pm 3.2)$ & 1,083 & $( \pm 11)$ & 449,845 & $( \pm 13,337)$ \\
\hline \multicolumn{7}{|c|}{ Performance of the remanufacture plant } \\
\hline & & & Mean & SD & & \\
\hline & & Yield (\%) & 87.9 & $( \pm 0.1)$ & & \\
\hline \multicolumn{3}{|c|}{ Capacity utilisation (\%) } & 49.4 & $( \pm 0.9)$ & & \\
\hline \multicolumn{3}{|c|}{ Operational availability (\%) } & 94.3 & $( \pm 0.5)$ & & \\
\hline \multicolumn{3}{|c|}{ Overall process effectiveness (\%) } & 40.9 & $( \pm 1.1)$ & & \\
\hline
\end{tabular}




\begin{tabular}{|c|c|c|c|c|c|c|}
\hline \multirow[t]{2}{*}{ Service Contract } & \multicolumn{2}{|c|}{ On-time delivery (\%) } & \multicolumn{2}{|c|}{ Total received (unit) } & \multicolumn{2}{|c|}{ Profits-Loss (£/per year) } \\
\hline & Mean & SD & Mean & SD & Mean & SD \\
\hline $\mathrm{SC} 01$ & 82.0 & $( \pm 1.9)$ & 6,807 & $( \pm 180)$ & 314,371 & $( \pm 9,866)$ \\
\hline $\mathrm{SC} 02$ & 73.2 & $( \pm 2.3)$ & 5,146 & $( \pm 61)$ & 307,820 & $( \pm 13,075)$ \\
\hline $\mathrm{SC} 03$ & 85.3 & $( \pm 2.7)$ & 3,103 & $( \pm 67)$ & 168,934 & $( \pm 9,765)$ \\
\hline $\mathrm{SC} 04$ & 72.7 & $( \pm 1.6)$ & 9,047 & $( \pm 302)$ & 205,814 & $( \pm 8,389)$ \\
\hline $\mathrm{SC} 05$ & 74.2 & $( \pm 4.1)$ & 2,838 & $( \pm 12)$ & 398,876 & $( \pm 30,888)$ \\
\hline \multicolumn{7}{|c|}{ Performance of the remanufacture plant } \\
\hline & & & Mean & SD & & \\
\hline & & Yield (\%) & 88.0 & $( \pm 0.1)$ & & \\
\hline \multicolumn{3}{|c|}{ Capacity utilisation (\%) } & 68.6 & $( \pm 1.6)$ & & \\
\hline \multicolumn{3}{|c|}{ Operational availability (\%) } & 94.6 & $( \pm 0.2)$ & & \\
\hline \multicolumn{3}{|c|}{ Overall process effectiveness (\%) } & 57.1 & $( \pm 1.4)$ & & \\
\hline
\end{tabular}

Confidence Interval: 95 percent;

From year 2 until the end of the service contract, an increment of $20 \%$ was inserted in both SC02 and SC04 contracts. Thus, the remanufacturing company must deliver more recovered power transformers compared to that of the contract design stage. Simulation results have shown unsatisfactory performance achievements for the SCs. In particular, the OTD index for the first, second, fourth and fifth SCs $(82.0 \%, 73.2 \%, 72.7 \%$, and $74.2 \%$ respectively) reveals that additional demand can negatively affect other contract performances with possible contract disruption. In spite of this business opportunity, service providers cannot risk the achievements of the other SCs to meet customers' demands. By running the sensitivity analysis using the decision support module, experiment results have shown a maximum allowed increment around of $9 \%$ on the transform return rate without reducing the performance of other SCs.

\section{CONCLUDING REMARKS AND FUTURE WORK}

This paper discusses the use of symbiotic simulation for decision support in a remanufacturing system. The use of symbiotic simulation in this way has advanced the research domain in dealing with uncertainty, especially in predicting the outcomes from and performances of remanufacturing and product recovery management in general. The research has thus provided relevant contributions to the body of knowledge as follows. First, our research has extended the capabilities and addressed the limitations of traditional simulation in capturing current state parameters of the real system, in this case the remanufacturing system, into the simulation model, so as to more accurately simulate the remanufacturing system during the execution of a 
service contract, also known as the in-service phase. Second, these so-called symbiosis capabilities were purposely built in and added on to the existing remanufacturing model. The relationship between the simulation model and the real system resembles a symbiosis mutualism and they are now physically coupled so that any changes in the real system will be reflected in the simulation model. This is a significant contribution to the process simulation modelling research, especially in the midst of the digital transformation of the manufacturing and service worlds. Third, the advancements in the simulation technology have subsequently extended the decision-making capabilities that were previously restricted by the fact that the simulation was used only during the design phase of a system. The symbiosis characteristics allow the simulation model to be used as the twin of the real system (hence digital twins).

The implications to the above technological contributions are that the symbiotic simulation is ideal for decision-making applications of SCs, particularly over the entire contract execution phase. To deal with the potential discrepancies between the designed service contract performance and those obtained in practice, the service provider must somehow continuously monitor the remanufacturing system operations and service performance until the end of the SCs' duration. Nonetheless, frequently occurring complexities in the existing remanufacturing system make the monitoring of service performance difficult, leading to the inaccurate measurement of business outcomes.

Unpredictable circumstances can significantly affect the outcomes of the business performance of the remanufacturing systems. Uncertainty in product recovery time and cost can disturb production and inventory control that might jeopardise the service performance. Moreover, customer revision of demand whilst the contract is running often needs a tremendous effort from the service provider to carry out a CBA. Supplementary methods and procedures to better monitor performance levels can contribute to the increased competitiveness of the service provider. With symbiotic simulation, unexpected variations typically found in remanufacturing systems can be incorporated in the simulation model in real-time. The simulation users can subsequently track revenues and costs of the remanufacturing SCs.

The proposed SSS promotes the physical link between the simulation model and the remanufacturing system. Managers and industrial engineers can develop the simulation models where product recovery operations, process, and routines are mapped from the remanufacturing systems and linked to the simulation model dynamically. In particular, data-to-information 
conversion modules with learning mechanisms can catch behaviours, tendencies, and hidden knowledge from SCs aiming to enrich virtual representation of remanufacturing systems. A simulation model driven by remanufacturing system data can provide an effective way to better manage service contract execution allowing robust modification of contract terms and conditions.

A power transformer remanufacturing system was selected as the industrial case for this study. Detailed analyses of the power transformer remanufacturing process, operations, and routines were carried out and used to design a symbiotic simulation model. Additionally, performance measures and KPIs from commercial and production plant perspectives were catalogued and included in commercial and CBA modules from the simulation model. Plant process capability variation and service contract clause modifications, which are principal issues in power transformer remanufacture, were used as a proof of concept in this research. Moreover, some hypothetical events whilst service contracts were running were also considered in the experiment throughout what-if scenarios.

Results obtained from first experiment suggest that service contract KPIs may be affected by lower plant performance levels. In order to avoid contract penalties or possible interruptions, service providers must start a proactive reaction as soon as performance degradation arises. Using a symbiotic simulation model, service providers could, for instance, add supplementary work shifts minimizing maintenance and repair time in order to maintain desired plant capability. Second the experiment investigated the potential business opportunity by attempting to deal with a particular customer's demand. Simulated results suggested that the desired increase in transform return rate will exceed the remanufacturing system capability. Running a simulation model with a sensitivity analysis on a lower increase threshold on the monthly average of transformer remanufactured could be found without risking other SCs' performance. Thus, service providers could better negotiate business opportunities without penalising other SCs.

As a data driven simulation method, an SSS seems to be a prospective way to contribute with cyber-physical system. It can provide required assistance to deal with complex interactions and interoperability which appear in remanufacturing systems. Furthermore, symbiotic simulation seems to be a feasible way to recalibrate a simulation model using physical system data. Parameters and components from simulation model can adapt to dynamic changes, thus better 
representing remanufacturing systems. Closing the simulation model to the physical system makes simulation outputs more reliable and with a trustable decision support. Further research agenda are necessary to better understand the symbiotic simulation use in remanufacturing systems. In addition, more industrial case studies and practical applications are needed to test the simulation model and the symbiotic remanufacturing system. Similarly, more historical and empirical data are necessary to increase simulation model accuracy. Symbiotic modelling and simulation with adaptive and autonomic decision support application (Mitchell and Yilmaz 2008) could complement the understanding of remanufacturing systems with multi-customers' requirements with high variation in demand and supply of used products.

\section{REFERENCES}

Aksoy, H. Kıvanç, and Surendra M. Gupta. "Near optimal buffer allocation in remanufacturing systems with N-policy.” Computers \& Industrial Engineering (Elsevier) 59 (2010): 496508 .

Ali-Marttila, Maaren, Salla Marttonen-Arola, Timo Kärri, Olli Pekkarinen, and Minna Saunila. "Understand what your maintenance service partners value." Journal of Quality in Maintenance Engineering 23 (2017): 144-164.

Calvi, K., S. Chung, M. Economou, R. Kulkarni, and R. Havens. "Dedicated refurbishing line optimization by simulation." 2015 IEEE International Conference on Industrial Engineering and Engineering Management (IEEM). 2015. 1262-1266.

Clottey, Toyin, W. C. Benton, and Rajesh Srivastava. "Forecasting Product Returns for Remanufacturing Operations.” Decision Sciences (Blackwell Publishing Inc) 43 (2012): 589-614.

Dal, Bulent, Phil Tugwell, and Richard Greatbanks. "Overall equipment effectiveness as a measure of operational improvement - A practical analysis." International Journal of Operations \& Production Management 20 (2000): 1488-1502.

Famili, A., Wei-Min Shen, Richard Weber, and Evangelos Simoudis. "Data preprocessing and intelligent data analysis.” Intelligent data analysis (IOS Press) 1 (1997): 3-23.

Fanchao, Z., S. J. Turner, and H. Aydt. "Symbiotic simulation control in supply chain of lubricant additive industry." 2009 13th IEEE/ACM International Symposium on Distributed Simulation and Real Time Applications. 2009. 165-172. 
Frimpong, G. K., T. V. Oommen, and R. Asano. "A survey of aging characteristics of cellulose insulation in natural ester and mineral oil.” IEEE Electrical Insulation Magazine 27 (2011): 36-48.

Galbreth, Michael Ryan. "Managing condition variability in remanufacturing." Ph.D. dissertation, 2006.

Gharbi, A., R. Pellerin, and J. Sadr. "Production rate control for stochastic remanufacturing systems." International Journal of Production Economics 112 (2008): 37-47.

Ghosh, Debabrata, Sirish Gouda, Ravi Shankar, Sanjeev Swami, and Vinu Cheruvil Thomas. "Strategic decision making under subscription-based contracts for remanufacturing." International Journal of Production Economics 200 (2018): 134-150.

Golinska-Dawson, Paulina, and Pawel Pawlewski. "Simulation Modelling of Remanufacturing Process and Sustainability Assessment." In Sustainability in Remanufacturing Operations, 141-155. Springer, 2018.

Graham, Ian, et al. "Performance measurement and KPIs for remanufacturing." Journal of Remanufacturing 5 (11 2015): 10.

Gregor, S., and A. R. Hevner. "Positioning and presenting design science research for maximum impact." MIS quarterly 37 (2013).

Grubbström, R. W., and O. Tang. "Optimal production opportunities in a remanufacturing system." International Journal of Production Research (Taylor \& Francis) 44 (2006): 3953-3966.

Hevner, A. R., S. T. March, J. Park, and S. Ram. "Design science in information systems research.” Management Information Systems Quarterly 28 (2008): 6.

Hevner, A., and C. Chatterjee. "Design science research in information systems." In Design research in information systems, 9-22. Springer, 2010.

Ilgin, Mehmet Ali, and Surendra M. Gupta. Remanufacturing modeling and analysis. CRC Press, 2012.

Kang, Hong-Yoon, Yong-Sung Jun, Young-Chun Kim, and Hyun-Jung Jo. "Comparative analysis on cross-national system to enhance the reliability of remanufactured products." Procedia CIRP (Elsevier) 40 (2016): 280-284.

Karim, M. A., P. Samaranayake, A. J. R. Smith, and S. K. Halgamuge. "An on-time delivery improvement model for manufacturing organisations." International Journal of Production Research (Taylor \& Francis) 48 (2010): 2373-2394. 
Kück, M., J. Ehm, T. Hildebrandt, M. Freitag, and E. M. Frazzon. "Potential of data-driven simulation-based optimization for adaptive scheduling and control of dynamic manufacturing systems.” Winter Simulation Conference (WSC), 2016. 2016. 2820-2831.

Lehr, Christian B., Jörn-Henrik Thun, and Peter M. Milling. "From waste to value - a system dynamics model for strategic decision-making in closed-loop supply chains." International Journal of Production Research (Taylor \& Francis) 51 (2013): 4105-4116.

Lorin, P., P. Khanna, P. Werle, and L. Eklund. "Transformer Condition Assessment: Methodologies and On-Site Repair Solutions.” IEEE Industry Applications Magazine 20 (9 2014): 50-57.

Low, M. Y. H., et al. "Symbiotic simulation for business process re-engineering in high-tech manufacturing and service networks.” 2007 Winter Simulation Conference. 2007. 568576.

Lund, R. T., and W. M.f Hauser. "Remanufacturing-an American perspective.” (IET) 2010.

Lundmark, Peter, Erik Sundin, and Mats Björkman. "Industrial challenges within the remanufacturing system." 3rd Swedish Production Symposium 2009, Göteborg. 2009. 132-138.

March, S. T., and V. C. Storey. "Design science in the information systems discipline: an introduction to the special issue on design science research.” MIS quarterly (JSTOR), 2008: 725-730.

Mashhadi, A. R., B. Esmaeilian, and S. Behdad. "Uncertainty Management in Remanufacturing Decisions: A Consideration of Uncertainties in Market Demand, Quantity, and Quality of Returns." ASCE-ASME Journal of Risk and Uncertainty in Engineering Systems, Part B: Mechanical Engineering, 2015.

Mitchell, Bradley, and Levent Yilmaz. "Symbiotic adaptive multisimulation: An autonomic simulation framework for real-time decision support under uncertainty." $A C M$ Transactions on Modeling and Computer Simulation (TOMACS) (ACM) 19 (2008): 2.

Mutingi, M., and M. Mhlanga. "System dynamics simulation for strategic green supply chain management." International Conference on Competitive Manufacturing. 2013.

Noack, Daniel, Marcin Mosinski, Oliver Rose, Peter Lendermann, Boon Ping Gan, and Wolfgang Scholl. "Challenges and solution approaches for the online simulation of semiconductor wafer fabs." Simulation Conference (WSC), Proceedings of the 2011 Winter. 2011. 1840-1851.

Parker, D., et al. "Remanufacturing Market Study.” Tech. rep., European comission, 2015. 
Peffers, Ken, Tuure Tuunanen, Marcus A. Rothenberger, and Samir Chatterjee. "A design science research methodology for information systems research." Journal of management information systems (Taylor \& Francis) 24 (2007): 45-77.

Poles, Roberto. "System Dynamics modelling of a production and inventory system for remanufacturing to evaluate system improvement strategies." International Journal of Production Economics (Elsevier) 144 (2013): 189-199.

Robotis, Andreas, Tamer Boyaci, and Vedat Verter. "Investing in reusability of products of uncertain remanufacturing cost: The role of inspection capabilities." International Journal of Production Economics 140 (2012): 385-395.

Savaskan, R. Canan, Shantanu Bhattacharya, and Luk N. Van Wassenhove. "Closed-loop supply chain models with product remanufacturing.” Management science (Informs) 50 (2004): 239-252.

Sharpe, Richard G., Paul A. Goodall, Aaron D. Neal, Paul P. Conway, and Andrew A. West. "Cyber-Physical Systems in the re-use, refurbishment and recycling of used Electrical and Electronic Equipment." Journal of cleaner production (Elsevier) 170 (2018): 351361 .

Slotina, Lasma, and Elina Dace. "Decision support tool for implementation of remanufacturing in an enterprise." energy Procedia (Elsevier) 95 (2016): 451-458.

Smith-Gillespie, Aleyn, Ben Peace, Ben Walsh, and David Stewart. "Supporting Excellence in UK Remanufacturing Produced: Stakeholder dialogue on opportunities and challenges." Tech. rep., Carbon Trust, https://www.carbontrust.com/resources/reports/advice/supporting-excellence-in-ukremanufacturing/, 2014.

Statham, Steve. "Remanufacturing towards a more sustainable future." Electronics-enabled Products Knowledge-transfer Network, 2006: 4.

Teixeira, Evandro Leonardo Silva, Benny Tjahjono, and Sadek Crisóstomo Absi Alfaro. “A novel framework to link prognostics and health management and product--service systems using online simulation.” Computers in Industry (Elsevier) 63 (2012): 669-679.

Tjahjono, B. "Supporting shop floor workers with a multimedia task-oriented information system". Computers in Industry, 60(4), 257-265.

Tjahjono, B., and X. Jiang. "Linking symbiotic simulation to enterprise systems: framework and applications.” 2015 Winter Simulation Conference (WSC). 2015. 823-834. 
Tjahjono, B., E. L. S. Teixeira, and S. C. A. Alfaro. "An online simulation to link asset condition monitoring and operations decisions in through-life engineering services." 2013 Winter Simulations Conference (WSC). 2013. 159-168.

U.S. International Trade Commision. "Remanufactured goods: An overview of the US and global industries, markets, and trade.” USITC Publication 4356 (2012): 332-525.

Umeda, S. "Simulation analysis of supply chain systems with reverse logistics." 2013 Winter Simulations Conference (WSC). 2013. 3375-3384.

Von Alan, R. Hevner, Salvatore T. March, Jinsoo Park, and Sudha Ram. "Design science in information systems research." MIS quarterly (Springer) 28 (2004): 75-105.

Wang, Shanshan. "Modeling supply chain dynamics with calibrated simulation using data fusion." Ph.D. dissertation, Arizona State University, 2010.

Wang, Xi Vincent, and Lihui Wang. "Digital twin-based WEEE recycling, recovery and remanufacturing in the background of Industry 4.0." International Journal of Production Research (Taylor \& Francis), 2018: 1-11.

Wynn, Moe Thandar, Marlon Dumas, Colin J. Fidge, Arthur H. M. Hofstede, and Wil M. P. Aalst. "Business Process Simulation for Operational Decision Support." In Business Process Management Workshops: BPM 2007 International Workshops, BPI, BPD, CBP, ProHealth, RefMod, semantics4ws, Brisbane, Australia, September 24, 2007, Revised Selected Papers, edited by Arthur Hofstede, Boualem Benatallah and Hye-Young Paik, 66-77. Berlin, Heidelberg: Springer Berlin Heidelberg, 2008.

Yanikara, F. S., and M. E. Kuhl. "A simulation framework for the comparison of reverse logistic network configurations.” 2015 Winter Simulation Conference (WSC). 2015. 979-990.

Zhang, Yingfeng, et al. 'The 'Internet of Things' enabled real-time scheduling for remanufacturing of automobile engines." Journal of cleaner production (Elsevier) 185 (2018): 562-575. 